\title{
Hyper-X Mach 10 Engine Flowpath Development: Fifth Entry Test Conditions and Methodology
}

\author{
R. J. Bakos", C.-Y. Tsait; GASL, Inc., Ronkonkoma, NY 11779 \\ R. C. Rogers $\ddagger$ and A. T. Shihs; NASA-LaRC, Hampton, VA 23681
}

\section{ABSTRACT}

A series of Hyper-X Mach 10 flowpath ground tests are underway to obtain engine performance and operation data and to confirm and refine the flowpath design methods. The model used is a full-scale height, partial-width replica of the Hyper-X Research Vehicle propulsive flowpath with truncated forebody and aftbody. This is the fifth test entry for this model in the NASA-HYPULSE facility at GASL. For this entry the facility nozzle and model forebody were modified to better simulate the engine inflow conditions at the target flight conditions. The forebody was modified to be a wide flat plate with no flow fences, the facility nozzle Mach number was increased, and the model was positioned to be tested in a semi-directconnect arrangement. This paper presents a review of the test conditions, model calibrations, and a description of steady flow confirmation. The test series included runs using hydrogen fuel, and a silane-in-hydrogen fuel mixture. Other test parameters included the model mounting angle (relative to the tunnel flow), and the test gas oxygen fraction to account for the presence of [NO] in the test gas at the M10 conditions.

\section{INTRODUCTION}

NASA's hypersonic research vehicle, Hyper-X will fly the third of its series of autonomous scramjet powered vehicle tests at a nominal Mach number of 10 . Development of the engine flowpath for this flight has been ongoing in the NASA-HYPULSE Facility at GASL since late 1998. The Mach 10 HYPULSE tests have focused on confirmation of the scramjet flowpath design methodology. This effort follows testing at Mach 7 to benchmark this pulse-test facility against the extensive ground test facility database coming from blowdown tunnels at NASA-Langley. Details of the NASA Hyper-X Program and descriptions of the ground test plans have been presented in several
references. ${ }^{[1-3]}$

At present, only pulse facilities are capable of reaching the energy levels and pressures required for Mach 10 propulsion testing. These facilities achieve steady flow conditions for a very short time and require special attention to data acquisition, using high frequency response instrumentation, as well as to verification of established steady flow through the test engine. In all other ways, however, the resulting test data and interpretation are similar to that from conventional, long-duration facilities. The Hyper- $X$ Mach 10 engine will be the first propulsive engine developed exclusively in a pulse-type test facility.

The HYPULSE facility, which is located at and operated by GASL, Inc., is a shock-tunnel-type pulse facility that can be configured as a detonation-driven reflected-shock tunnel (RST) to achieve test conditions that duplicate the stagnation enthalpy encountered at Mach 5 to $10+$ flight speeds. HYPULSE has a test chamber that allows testing of a subscale scramjet engine of the same scale as NASA Langley conventional blow-down test facilities. ${ }^{[4]}$ More information about the operation of HYPULSE and facility test capabilities is given in references. $^{[5-7]}$

The first entry tests conducted in HYPULSE in support of the Hyper-X Program were at Mach 7 conditions and provided a benchmark of these pulse-facility data to the extensive ground test database available from blowdown facilities at NASA Langley. ${ }^{[8]}$ Subsequent test entries have been aimed at building a database of the Hyper$X$ Mach 10 flowpath at local test conditions that replicate those over a portion of the target Mach 10 flight flowpath.

These tests have all used the HYPULSE Scramjet Model (HSM). This model was designed to provide an identical piece of

\footnotetext{
Senior Member AIAA, † Member AIAA, $\ddagger$ Senior Member AIAA, §Member AIAA
} 
flowpath test hardware between HYPULSE and other conventional scramjet test facilities at LaRC for Mach 7 tests; and to be easily modified to accept the Mach 10 flowpath lines as they evolved through the test program. The HSM is a partial width, with a truncated forebody and aftbody, that replicates the central portion of the Hyper-X scramjet flowpath.

Initial Mach 10 entries focused on test methodology development, establishing test conditions, and gathering initial flowpath performance data. In this fifth entry, test methodology improvements continue as does the refinement of test conditions to improve flow quality and to better match flight conditions that have evolved with adjustments to the planned Mach 10 flight trajectory. The HYPULSE facility nozzle and the HSM were modified to improve the quality of the captured flow and to better duplicate the combustor throat conditions expected at the target flight condition. These changes included the fabrication of a smaller throat piece for the facility nozzle to yield an exit Mach number closer to that expected at the inlet plane in Mach 10 flight. In addition, the HSM was modified to replace the forebody with a flat plate of a width sufficient to give a twodimensional streamtube at the cowl inlet plane, which eliminated the need for forebody fences.

The objectives of this HSM fifth entry test series were to obtain Mach 10 Hyper-X scramjet flowpath operation data at more flight-like conditions and to use these data to provide performance estimates for comparison with the engine design methodology. This paper will provide a review of the test conduct, flow condition calibration, and the test data processing methods. All tests have been conducted at conditions duplicating the Hyper- $X$ Mach 10 flight enthalpy.

\section{TEST CONDITIONS}

\section{HYPULSE REFLECTED-SHOCK TUNNEL}

Description: The NASA HYPULSE shock tunnel facility, shown in Figure 1, was operated in reflected-shock tunnel (RST) mode at Mach 10 conditions in these fifth entry tests of the HYPULSE Scramjet Model (HSM). The test medium in HYPULSE is shock-heated air, with the shock wave generated by a hydrogenoxygen-argon detonation wave that is initiated by a cold helium driver at up to $12,000 \mathrm{psi}$. The reflection of the shock at the facility nozzle interface produces the nozzle plenum state at conditions near stagnation conditions. The test chamber is a 19-foot long, 7-foot diameter section that contains the facility nozzle and the HSM that replicates the internal Hyper- $X$ Mach 10 flowpath. The run times of HYPULSE are short, on the order of a few milliseconds of established flow. At the Mach 10 conditions, nozzle exit conditions simulate flight speeds with a test gas velocity of about $10 \mathrm{ft} / \mathrm{ms}$. Test model length is, therefore, limited to about 7 feet to ensure the passage of three model lengths of test gas flow during the nominal $2 \mathrm{~ms}$ of steady flow.

\section{MACH 10 OPERATION}

Nozzle Reservoir Conditions: Conditions are determined from measured parameters in the shock tube, combined with calculations of the flow in the tube end. The shock speed is measured and used with a one-dimensional shock stagnation calculation that assumes thermal-chemical equilibrium. From the shock speed and shock-tube fill pressure, provisional reservoir conditions are calculated as those behind a reflected normal shock of strength sufficient to bring the test gas velocity to a value consistent with choked mass flow through the nozzle throat. Including this slight forward velocity lowers the provisional reservoir pressure and temperature slightly. Non-ideal behavior in the nozzle reservoir causes the measured reservoir pressure to differ from the provisional value. An adjustment is necessary and is accomplished assuming isentropic expansion or compression of the provisional conditions to the measured pressure.

Facility Nozzle: For these fifth entry test series the nozzle was modified to reduce the throat diameter in the conical section from the original 2.00 -inch to 1.75 -inch. The nozzle now has a geometric area ratio of about 225 (henceforth referred to as the AR-225 nozzle) and a nominal exit Mach number of 6.9 , as computed with $\mathrm{CFD}^{[9]}$ from the nozzle plenum at nominal Mach 10 enthalpy conditions.

The nozzle calculations were carried out using GASP v3.2.5 from Aerosoft ${ }^{(\mathbb{E}}$. The calculation used Finite rate chemistry (Kang/Dunn Model, 5 species). Transition was enforced at $x=1.76$ in. from the nozzle throat. The grid size was $65 \times 129 \times 2$ : subsonic section, and $449 \times 129 \times 2$ : 
supersonic section. The Mach number contours resulting from the run are shown in Figure 2. The CFD solution indicated a nozzle exit core flow that was reasonably uniform over about 18 inches.

Test Conditions: The nominal test conditions were determined from the GASP CFD solution. Conditions in the nozzle exit core flow were determined using a mass-flux weighted averaging procedure. These nominal conditions for Mach 10 operation are given in Table 1. The baseline values of pressure, temperature, and velocity at the nozzle exit were estimated by adjusting the CFD results to the measured plenum conditions of the exit pitot survey test run E91. These conditions are used as a reference set for subsequent test conditions and HSM operation.

Table 1. Nominal Mach 10 test conditions for HSM $5^{\text {th }}$ Entry tests.

\begin{tabular}{|c|c|c|c|c|c|c|c|c|c|c|c|}
\hline \multicolumn{12}{|c|}{\begin{tabular}{|l} 
UNCLASSIFIED \\
\end{tabular}} \\
\hline & \multicolumn{3}{|c|}{ Reservoir (stagnation) } & \multicolumn{8}{|c|}{ AR-225 HYPULSE Nozzle exit } \\
\hline \multirow{2}{*}{$\begin{array}{l}\text { Flight } \\
\text { Mach }\end{array}$} & \multirow{2}{*}{$\begin{array}{l}\mathrm{H} \\
(\mathrm{Btu} / \mathrm{b}) \\
{[\mathrm{MJ} / \mathrm{Kg}]}\end{array}$} & \multirow{2}{*}{$\begin{array}{l}\mathrm{P} \\
\text { (psia) } \\
\text { [MPa] }\end{array}$} & \multirow{2}{*}{$\begin{array}{l}\mathrm{T} \\
(\mathrm{R}) \\
{[\mathrm{K}]} \\
\end{array}$} & \multirow[b]{2}{*}{ M } & \multirow{2}{*}{$\begin{array}{l}\mathrm{P} \\
\text { (psia) } \\
\text { [kPa] }\end{array}$} & \multirow{2}{*}{$\begin{array}{l}\mathrm{T} \\
(\mathrm{R}) \\
{[\mathrm{K}]}\end{array}$} & \multirow{2}{*}{$\begin{array}{l}V \\
\text { (fps) } \\
{[\mathrm{m} / \mathrm{s}]}\end{array}$} & \multicolumn{4}{|c|}{ Composition (mass fraction) } \\
\hline & & & & & & & & $\mathrm{N}_{2}$ & $\mathrm{O}_{2}$ & NO & 0 \\
\hline $\begin{array}{l}10 \\
\text { (BL:E91) }\end{array}$ & $\begin{array}{l}2101 \\
4.887\end{array}$ & $\begin{array}{l}3432 \\
23.67\end{array}$ & $\begin{array}{l}6952 \\
3862\end{array}$ & 6.91 & $\begin{array}{l}0.416 \\
2.870\end{array}$ & $\begin{array}{l}846 \\
470\end{array}$ & $\begin{array}{l}9836 \\
2998\end{array}$ & 0.7374 & 0.1964 & 0.0647 & 0.0016 \\
\hline
\end{tabular}

\section{HYPER-X ENGINE FLOWPATH MODEL}

\section{FLOWPATH SIMULATION}

The test hardware for these tests is the HYPULSE Scramjet Model (HSM) as modified to provide better simulation of the combustor entrance conditions at the target Mach 10 flight condition. The relation of the HSM to the Hyper$X$ Research Vehicle (HXRV) propulsion flowpath is shown in Figure 3. As illustrated in Figure 3, the HSM is a full scale, partial width and length replica of the Hyper-X Research Vehicle (HXRV) propulsion flowpath, with the forebody and aftbody (nozzle) truncated to achieve a model size compatible with the facility limitations. Overall length of the HSM is about 70 inches. The HSM was modified from previous test entries to replicate the HXRV forebody ramp, which was extended forward to the first forebody compression corner on the HXRV, as indicated by the broken line on the HXRV side view.

In scramjet engine ground tests, it is typically desirable to replicate flight values of the stagnation enthalpy, Mach number, and static pressure at the engine inlet (cowl) plane, as given in the figure. As indicated in Table 1, HYPULSE operation with AR-225 nozzle gives exit conditions with a higher Mach number and lower pressure than target flight values at the cowl.
To adjust the conditions, the forebody ramp of HSM is set to generate a shock wave that raises the pressure and reduces the Mach number at the cowl plane. At an angle of $5.5^{\circ}$, the pressure matches flight, but at lower Mach number, at $1^{\circ}$ the Mach number is matched but at lower pressure. The former conditions were taken as the baseline at which the majority of tests were run.

\section{HYPULSE SCRAMJET HARDWARE}

Forebody Model: The HSM forebody was modified to overcome difficulties encountered in connecting the test flow conditions and observed characteristics with the CFD flow predictions and data analyses, which were encountered in the previous Mach 10 entries. These modifications were to make a flat forebody (FB) that was wide enough (19 inches) to yield a two-dimensional flow at the inlet (cowl) plane without the need of fences. The design rationale to decide the FB width and compute the expected inlet flow uniformity are presented in reference 9 .

A boundary layer trip (BLT) strip was designed for the nominal conditions of the AR225 nozzle with expected boundary layer transition occurring at a station 8-9 inches downstream. A photo of the HSM with the flat FB is shown in Figure 4. 


\section{TEST HARDWARE INSTALLATION}

Figure 5 shows a sketch of the HSM configuration as mounted cowl side up in the HYPULSE test chamber at the baseline $5.5^{\circ}$ angle to the tunnel flow. The model is positioned with the FB leading edge outside the nozzle exit plane to enable FB schlieren, which is accessible through the circular windows in the test chamber. Optical access (for schlieren) to the engine isolator and combustor is obtained through the rectangular windows on the HSM side wall in line with the third circular window.

\section{INSTRUMENTATION}

Surface Data: instrumentation layout on the body and cowl side surfaces of the HSM includes 184 pressure and heat flux instrument ports. $\mathrm{PCB}$ pressure transducers are used and are recess mounted behind .063-inch diameter, .06-inch deep orifices. The platinum thin-film heat flux gages are flush mounted.

Optical Diagnostics: As indicated in Figure 5, the HSM has two sets of windows on each side to permit optical access to the isolatorcombustor and internal nozzle sections of the flowpath. The schlieren system uses a highpower LED as the light source, and four monochrome CCD cameras to capture sequential images of the flow field during a test run. ${ }^{[11]}$ For the images acquired in these tests, the LED pulse width was $4 \mu \mathrm{s}$ and the cameras were set at a shutter speed 1/16000 (62 $\mu \mathrm{s})$. In addition to providing a two-dimensional view of the test flow, the four-frame sequential schlieren (4FSS) images provide information about flow establishment and termination due to driver gas arrival.

\section{MODEL CALIBRATION TESTS}

Nozzle Exit Pitot A pitot rake with 27 probes spaced at 1.0-inch intervals across the nozzle exit surveyed the flow for comparison to CFD predictions. Figure 6 shows a schlieren of the pitot rake in test, and Figure 7 contains survey data and computational solutions at two axial planes, 1-inch and 13 inches downstream of the exit. These data helped to define the length of the test core at a position near the engine inlet capture plane. The agreement between the pitot data profiles and the CFD values is generally within about $+/-5 \%$ of the computed values. The pitot values for the CFD results were obtained using an equilibrium chemistry routine to compute the shock jump condition, and assuming isentropic stagnation processes.

Time traces of pitot pressure (taken as an average or 13 traces within the core region), in raw and reduced form are shown in Figure 8. The reduced form is the ratio of pitot pressure to reservoir pressure which achieves a constant value only after the nozzle starting process is complete.

Before forming this ratio, a time shift is necessary of one trace relative to the other due to the transit time of pressure information between measurement locations - in this case from the reservoir to the pitot rake plane. Due to the hypersonic flow conditions, the shift velocity is taken equal to the flow velocity with little error. To set a standard time base for all time traces from the reservoir and throughout the model, the model forebody leading edge (FLE) location has been chosen. All normalized time traces are shifted such that flow arrival time corresponds to that at the FLE.

The normalized trace in Figure 8 indicates that the nozzle is delivering steady flow, after $2.5 \mathrm{~ms}$ has elapsed.

Nozzle Exit Heat Flux: To confirm the stagnation enthalpy of the flow delivered by the nozzle, stagnation point heating measurements were done in two calibration tests. 0.75 -inch diameter Macor hemispheres, instrumented with platinum thin-film heat flux gages, were mounted on the nozzle centerline. The heat flux distribution on the hemispheres as compared to a Fay-Riddell calculation at the CFD computed nozzle conditions, is shown in Figure 9a. Raw and normalized heat flux are shown in Figure 9b. In this case the normalization is by the square-root of reservoir pressure consistent with heat flux dependence on pressure. Again, constancy of normalized heat flux indicates steady nozzle flow by $2.5 \mathrm{~ms}$.

Forebody Data: The HSM forebody pressure and heat flux distributions are compared with computational results in Figure 10. Figure 10(a) shows the averaged static pressure distribution from the forebody leading edge into the inlet of the engine and includes results from a 2-D CFD solution at the nominal test condition as given in Table 1. The averaged pressure data are obtained from all runs (17 runs) with air test gas 
for the HSM at the $5.5^{\circ}$ baseline position. Standard deviation error bars for the averaged pressures from the 17 runs are included on the data points. Both the data and CFD results have been scaled to a nominal plenum pressure of 3450 psia for the comparison. The rise in pressure on the forebody over the first 15 inches of the forebody most likely results from the modified nozzle area ratio. This results in off design nozzle operation and allows uncancelled waves to leave the nozzle. Downstream, the pressure agrees with computational predictions as the flow approaches the cowl plane.

Figure 11 is a schlieren showing approximately the first 12 inches of the forebody. The dual shock wave emanating from the forebody just downstream of the leading edge is the boundary layer tripping device. No anomalous waves are evident to explain the pressure disturbance seen in Figure 10(a). However, such images have been taken for many tests, and in some cases a very weak, downward running disturbance is barely visible that may be associated with the measured pressure bump. Further examination of this anomaly is ongoing, however, the flat static pressure downstream as the flow enters the engine suggests this disturbance has no effect on the engine operation.

Heat flux data and results from a boundary layer solution are presented in Figure 10(b) for those runs made to obtain pitot pressures of the streamtube captured by the engine. Two plots of the data are presented and a GASP CFD solution. The two sets of data results were obtained by averaging the heat flux data at different points in times during the pulse flow over the forebody. The earlier time $(2.75 \mathrm{~ms})$ result is indicated by the diamond symbol and shows a distinct transition at $X=12$ inches, where the flow transition was assumed in the CFD solution made with a sharp leading edge. This transition location was chosen based on pretest calculations to size and locate the $\mathrm{BLT} \mathrm{T}^{(10)}$. However, the heat flux values at a later time $(3.4 \mathrm{~ms})$, indicated by the triangle symbols, indicate that boundary layer transition has moved forward and agree better with a more gradual transition between $X=7$ and 12 inches ${ }^{[10]}$ Examination of the pressure data on the FB, and their standard deviations shows that pressure values have larger unsteadiness in this transition region than downstream. There is no significant effect on the absolute pressure values.
Forebody Pitot Surveys: As with other HSM tests, a series of pitot pressure survey tests were conducted to map the streamtube flow entering the engine. Two 23 probe pitot rakes were used to obtain 8 surveys of the forebody flow in four runs with the HSM at the $5.5^{\circ}$ baseline position. Each rake had probes spaced 0.20 inch apart, with the first probe 0.25 inches from the FB surface. The last run was made with the BLT strip removed but indicated no significant difference from the others. The surveys were made at the engine centerline and at lateral locations of $0.93,+/-1.88$ and $+/-2.88$ inches from the centerline. The averaged data from all runs along with standard deviations is presented in Figure 12 for two averaging windows, the first centered at $2.75 \mathrm{~ms}$ and the second at $3.4 \mathrm{~ms}$. A slight reduction in normalized pitot pressure, on the order of $5 \%$ is apparent.

Also included in the plot are results from the GASP CFD solution ${ }^{[9]}$.Computed pitot values were obtained using an equilibrium chemistry routine to compute the shock jump and isentropic stagnation conditions. The CFD solution over the HSM forebody started with the axisymmetric CFD profile at the nozzle exit so as to include any wave structure from the nozzle. Since the nozzle CFD solution indicated chemically frozen flow, FB CFD solutions were made with frozen composition at the computed nozzle exit values.

Engine Flow Establishment: Normalized pressure traces on the forebody and in the engine are shown in Figure 13a and 13b. The forebody flow stabilizes very quickly, by just over $2 \mathrm{~ms}$, and remains steady out to $5 \mathrm{~ms}$. This particular engine test was fueled at a nominal test equivalence ratio, and with a small fraction of the hydrogen fuel replaced by silane, a pyrophoric gas commonly used to enhance ignition in scramjet engines. The engine pressure appears to stabilize only by $2.75 \mathrm{~ms}$, and then begins to fall after $4 \mathrm{~ms}$.

Critical to engine performance assessment are the integrated pressures measured in the thrust producing regions of the engine, and the integrated mass flux that enters the engine. These values need to be steady during the period when "steady" data is extracted. Figure $14 \mathrm{a}$ shows an engine nozzle pressure-area integral, normalized by reservoir pressure, for a 
fuelled combustion test. It indicates steady thrust occurs after about $2.5 \mathrm{~ms}$. Mass flow establishment is indicated as thrust normalized by CLE pitot pressure in Figure 14b. Thrust and mass flow appear to track together from approximately $2 \mathrm{~ms}$ on. The pitot data available for this comparison comes from a different run, and happens to be quite noisy, which drives the oscillations shown in the normalized trace.

Working from the foregoing steady flow establishment data, the time between $2.75 \mathrm{~ms}$ and $4.0 \mathrm{~ms}$ is considered nominally steady state for the test data. Some elements of the data, specifically the pitot pressure at the cowl leading edge, and the location of transition as measured from heat flux data on the forebody, show some changes with time, however, there appears to be no significant change in engine operating parameters as a result of these forebody changes.

\section{SUMMARY}

The paper presented a review of the test effort including calibrations and interpretation methods of the test data from the fifth entry of the HYPULSE Scramjet Model (HSM) as a part of the Hyper-X Mach 10 flowpath development effort. In the current test series, both the HYPULSE facility nozzle and the HSM were modified to achieve a better ground test simulation at the engine inlet plane for a M10 flight. The baseline test configuration was HSM with a wide flat-plate forebody without flow fences, positioned at an angle of $5.5^{\circ}$ relative to the tunnel flow. These tests were focused on determining the engine mass capture, and investigating the flowpath operation at conditions duplicating Mach10 flight enthalpy for hydrogen and silane hydrogen fuel mixtures. These tests provided a means to improve the Mach 10 engine test technique in HYPULSE, and to refine the data processing procedures. The main objective of the tests was to acquire a set of test data in the conditions closer to the target M10 flight conditions than all previous test series, hence, to provide a better database for comparison with design methods, to identify additional design modifications in aiding the final selection of Mach 10 flowpath design.

\section{REFERENCES}

1. McClinton, C. R.; et. al:: Hyper-X Wind Tunnel Program. AIAA Paper 98-0553, Jan. 1998.

2. Voland, R. T.; et. al: Hyper-X Engine Design and Ground Test Program. AlAA 98-1532, April 1998.

3. McClinton, C. R.; et. al.: Wind Tunnel Testing, Flight Scaling and Flight Validation with Hyper-X. AIAA Paper 982866, June 1998.

4. Guy, R. W.; Rogers, R. C.; Puster, R. L.; Rock, K. E.; and Diskin, G. S.: The NASA Langley Scramjet Test Complex. AIAA Paper No. 96-3243. July 1996.

5. Bakos, R. J.; et. al.: An Experimental and Computational Study Leading to New Test Capabilities for the HYPULSE Facility with a Detonation Driver. AIAA Paper 96-2193, June 1986.

6. Bakos, R. J.; et. al.: Design, Calibration, and Analysis of a Tunnel Mode of Operation for the HYPULSE Facility. AIAA Paper 96-2194, June 1996.

7. Modroukas, D.; Betti, A.; Chinitz, W.; and Bakos, R. J.: Design, Fabrication, and Calibration of a Mach 6.5 Hypersonic Shock Tunnel Nozzle for Scramjet Testing Applications. AIAA Paper 98-2496, June 1998.

8. Bakos, R.; Tsai, C-Y.; Rogers, R.C.; and Shih, A.: The Mach 10 Component of NASA's Hyper- $X$ Ground Test Program. ISABE-99-7216, September, 1999.

9. Tyll, Jason: CFD Calculation of the HSM, Mach 10 engine, KL7, Rectangular Forebody. GASL R\&AD TN-118; May 2000 (5923-301)

10. Dilley, A. D.: Private communication.

11. Tsai, C.y.; and Bakos, R. J.: Shock Tunnel Flow Visualization with a High Speed Schlieren and laser Holographic Interferometry System. AIAA Paper 982700, June 1998.

12. Chue, Randy: CFD Calculations of HYPULSE RST Nozzle with New Subsonic/Throat Section. GASL R\&AD Tech Note No. 107, Feb. 9, 2000. 


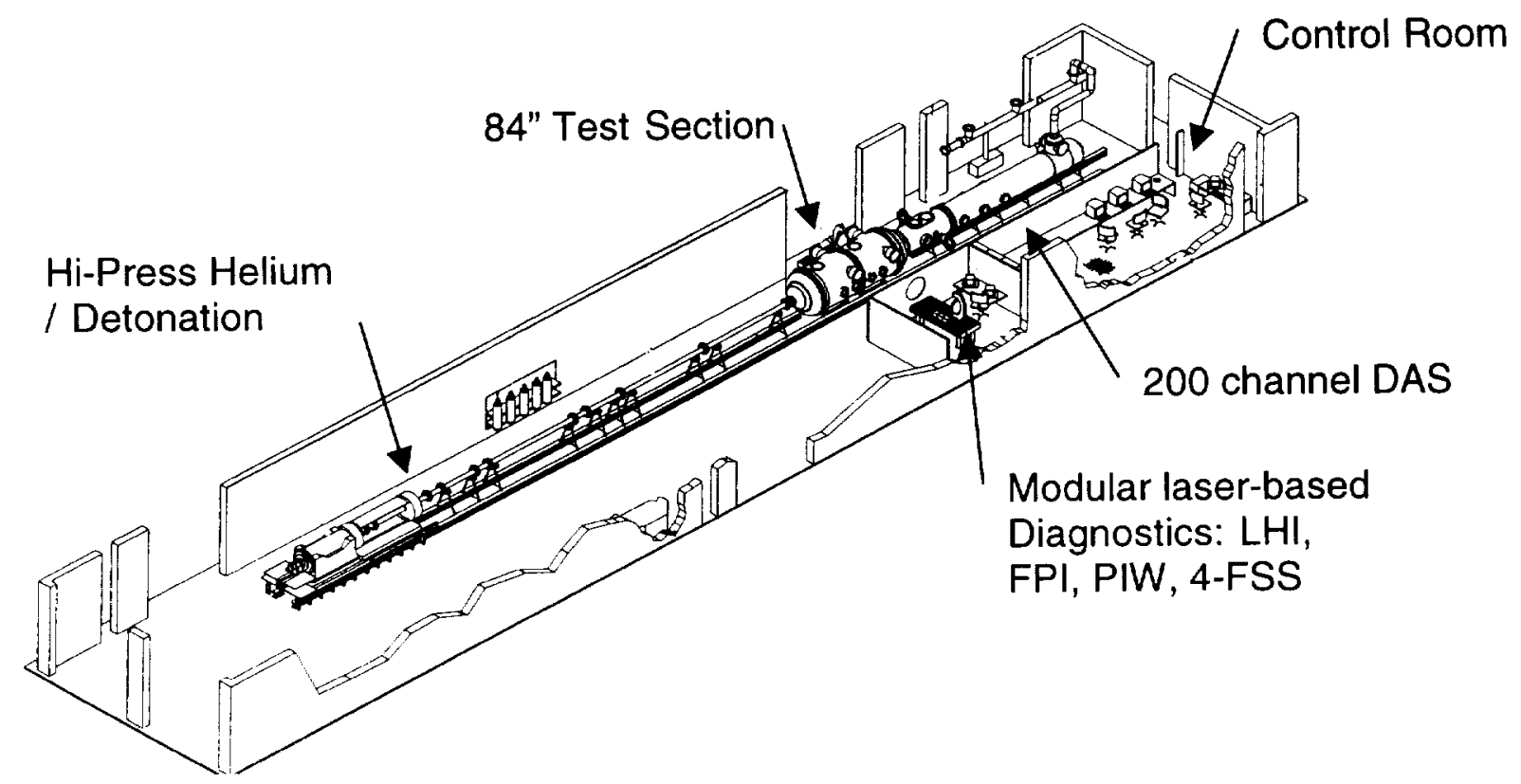

Figure 1. The NASA-HYPULSE Facility at GASL.
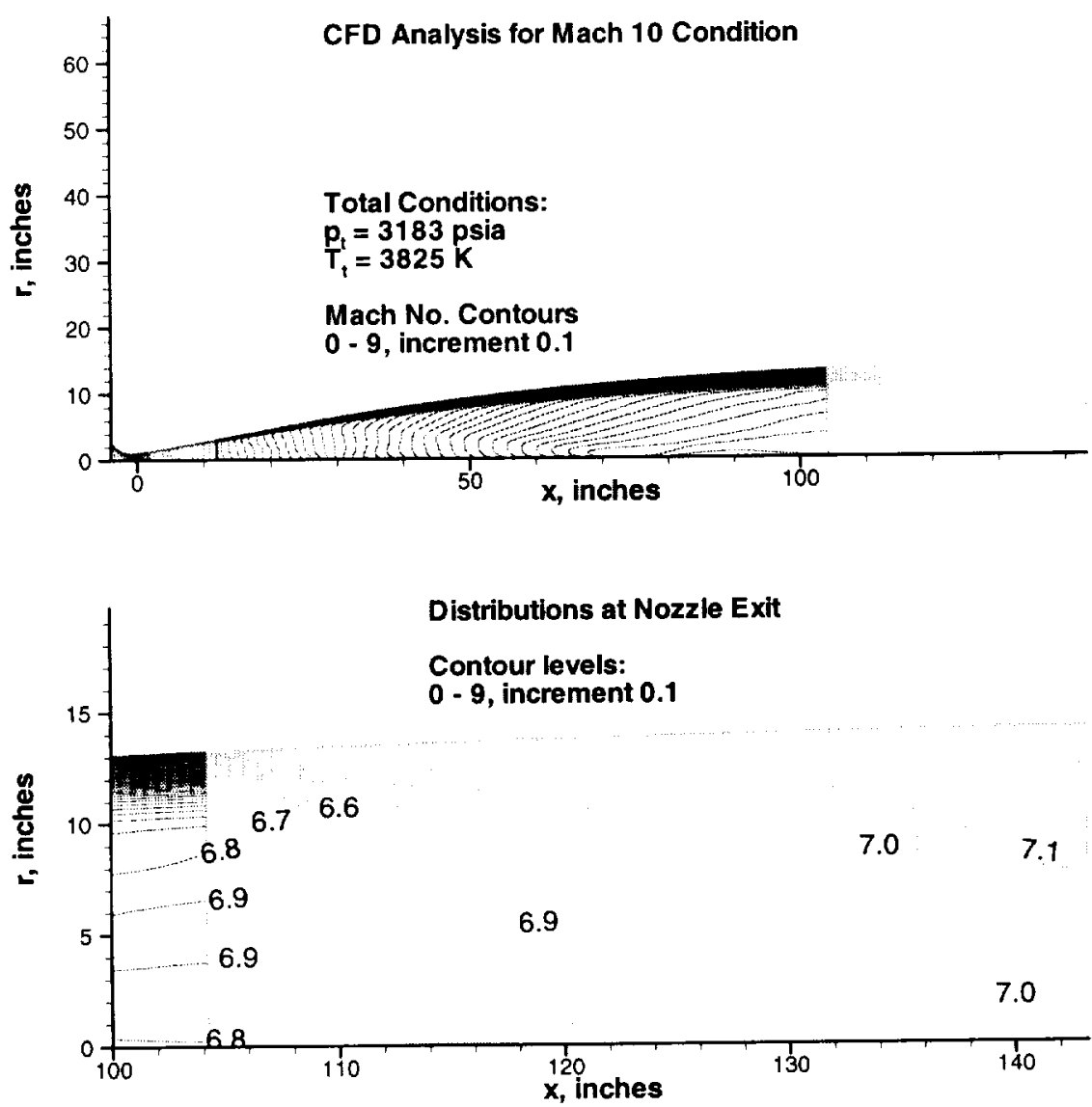

Figure 2. Mach number profiles for the AR225 nozzle as computed using GASP. 
June 14, 2001

\section{NASA STI Acquisitions DAA Authorization}

The following papers (copies enclosed) have been DAA approved as Unclassified, Publicly Available documents:

\section{Meeting Presentations:}

42rd AIAA/ASME/ASCE/AHS/ASC Structure \& Structural Dyn..., 4/16-19/2001, Seattle, WA:

B.H. Mason: Coupled Aerodynamic and Structural Sensitivity Analysis of a High-Speed...

M.D. Billings, et al:: Impact Test and Simulation of Energy Absorbing Concepts for...

M.C. Reaves, et al:: Test Cases for Modeling and Validation of Structures with...

I.S. Raju, et al.: Meshless Petrov-Galerkin Method Applied to Axisymmetric Problems.

7th AIAA/CEAS Aeroacoustics Conf. 5/28-30/2001, Maastricth, The Netherlands:

M.R. Khorrami, et al.: A Novel Approach for Reducing Rotor Tip-Clearance Induced...

F.W. Grosveld, et al.: Structural and Acoustic Numerical Modeling of a Curved Composite...

M.G. Jones, et al:: Comparison of Two Acoustic Waveguide Methods for Determining...

F. Farassat, et al:: The Detection of Radiated Modes From Ducted Fan Engines.

M.R. Khorrami, et al.: Time-Accurate Simulations and Acoustic Analysis of Slat Free...

R.H. Thomas, et al:: Computational Analysis of a Pylon-Chevron Core Nozzle Interaction.

American Helicopter Society 57th Annual Forum, 5/9-11/2001, Washington, DC:

K.H. Lyle, et al.: Evaluation of Test/Analysis Correlation Methods for Crash Applications.

J. Li, et al:: High Fidelity Failure Analysis for a Composite Fuselage Section.

G.B. Murr, et al.: Fatigue and Damage Tolerance Analysis of a Hybrid Composite Tapered...

R.G. Kvaternik, et al.: An Experimental Evaluation of Generalized Predictive Control...

D.D. Boyd, et al.: Analysis of Measured and Predicted Acoustics from an XV-15...

D.A. Piatak, et al.: A Wind-Tunnel Parametric Investigation of Tiltrotor Whirl-Flutter... NATO/RTO Symposium on Advanced Flow Management, Part A..., 5/7-11/2001, Loen, Norway:

J.M. Brandon, et al:: In-Flight Visualization Results of the F-106B with a Vortex Flap.

J.E. Lamar: Cranked Arrow Wing (F-16XL-1) Flight Flow Physics with CFD Predictions...

Tiltrotor/Runway Independent Aircraft Techn. \& Applications..., 3/20-21/2001, Arlington, TX:

B.D. Edwards, et al.: NASA/Army/Bell XV-15 Tiltrotor Low-Noise Terminal Area...

2nd Int'l Symp. of Atmospheric Reentry Vehicle \& Systems, 3/26-29/2001; Acrachon, France:

R.Mitcheltree, et al: An Earth Entry Vehicle for Returning Samples From Mars.

10th AIAA/NAL-NASDA-ISAS Int'l Space Planes \& Hypersonic.., 4/24-27/2001, Kyoto, Japan:

R.J. Bakos, et al.: Hyper-X Mach 10 Engine Flowpath Development: Fifth Entry Test...

D.E. Reubush, et al:: Hyper-X Stage Separation - Simulation Development and Results.

\section{Journal Article:}

D.D. Davis, et al.: Impact of Ship Emissions on Marine Boundary Layers...(GRL, 2001)

K.H. Rosenlof, et al.: Stratospheric Water Vapor Increases Over the Past Half...(GRL, 2001)

R.E. Southward, et al.: Reflective and Electrically Conductive Surface...(Prog Organic.. (2001)

P. Yang, et al.: Asymptotic Solutions for Optical Properties of Large...(Applied Optics, 2001)

J.F. Meyers, et al.: Characterization of Measurement Error Sources...(Meas. Sci. Techn., 2001) 
D.R. Ambur, et al.: Optimal Design of Grid-Stiffened Panels and Shells...(Comp. Struc., 2001) A. Tessler, et al.: A $\{1,2\}$-Order Plate Theory Accounting for Three...(Comp. Struc., 2001) L.M. Nicholson, et al.: Crosslink Density and Molecular Weight Effects on...(Poly. Prep., 2001)

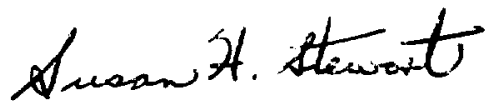

Susan H. Stewart

DAA Representative

NASA Langley Research Center

Mail Stop 196

Hampton, VA 23681-2199 s.h.stewart@larc.nasa.gov

phone: (757) 864-2518

fax: (757) 864-2375 